Geschichte der Antike 


\title{
GESCHICHTE DER ANTIKE
}

Ein Studienbuch

\author{
Herausgegeben von \\ Hans-Joachim Gebrke \\ und Helmuth Schneider
}

Mit 131 Abbildungen

Verlag J.B. Metzler

Stuttgart - Weimar 
Die Deutsche Bibliothek - CIP-Einheitsaufnahme

Geschichte der Antike : ein Studienbuch / hrsg. von Hans-Joachim Gehrke und Helmuth Schneider. - Stuttgart ; Weimar : Metzler, 2000

ISBN 978-3-476-01455-9

ISBN 978-3-476-01455-9

ISBN 978-3-476-03663-6 (eBook)

DOI 10.1007/978-3-476-03663-6

Dieses Werk einschließlich aller seiner Teile ist urheberrechtlich geschützt. Jede Verwertung außerhalb der engen Grenzen des Urheberrechtsgesetzes ist ohne Zustimmung des Verlages unzulässig und strafbar. Das gilt insbesondere für Vervielfältigungen, Übersetzungen, Mikroverfilmungen und die Einspeicherung und Verarbeitung in elektronischen Systemen.

(C) 2000 Springer-Verlag GmbH Deutschland

Ursprünglich erschienen bei J. B. Metzlersche Verlagsbuchhundlung und Carl Ernst Poeschel Verlag GmbH in Stuttgart 2000

www.metzlerverlag.de

info@metzlerverlag.de 


\section{INHALT}

Vorwort VII

Einleitung 1

Die Dark Ages und das archaische Griechenland

(Karl-Joachim Hölkeskamp/Elke Stein-Hölkeskamp) 17

Vom Palast zur Polis - die griechische Frühgeschichte

(K.-J. Hölkeskamp) 17

Die Welten des Homer

(E. Stein-Hölkeskamp) 44

Die Entstehung der Polis: Voraussetzungen und Bedingungen

(K.-J. Hölkeskamp) 58

Krise und Konsolidierung der Polis

(E. Stein-Hölkeskamp) 74

Die griechische Staatenwelt in klassischer Zeit (550-336 v.Chr.)

(Peter Funke) 97

Die „klassische“ Zeit als Epoche der griechischen Geschichte 97

Eine Geschichte der klassischen Zeit 100

Die Gesellschafts- und Staatsordnungen 134

Kulturgeschichtliche Grundlinien 156

Hellenismus (336-30 v. Chr.)

(Hans-Joachim Gehrke) 163

Der Hellenismus: Das Gesicht einer Epoche 163

Der politische Rahmen 165

Soziale Ordnung und politische Organisation 183

Wahrnehmung, Deutung, Weltvorstellung:

Der Hellenismus als kulturelles Phänomen 206

Der Hellenismus: Gemeinsame Phänomene einer Weltkultur 226

Rom von den Anfängen bis zum Ende der Republik (6. Jh. bis 30 v. Chr.)

(Helmuth Schneider) 229

Die Epochen der römischen Geschichte von den Anfängen bis zur

Begründung des Principats unter Augustus 229

Das frühe Rom 230

Die römische Republik im Zeitalter der außeritalischen Expansion 248

Das politische System, Wirtschaft und Gesellschaft 262

Kulturelle Entwicklung als Rezeptionsprozess 286

Krise und Zusammenbruch der römischen Republik 290 
Die römische Kaiserzeit (30 v.Chr. - 284 n.Chr.)

(Peter Herz)

Die historische Entwicklung 301

Strukturen der römischen Kaiserzeit 334

Die Spätantike (284-565 n.Chr.)

(Jens-Uwe Krause) 377

Einleitung 377

Politische Geschichte von Diocletianus bis Iustinianus 379

Verwaltung und Armee 393

Gesellschaft und Wirtschaft 405

Christentum 432

Anhang 449

Zeittafel 450

Stammtafeln 456

Die Achämeniden 456

Die Antigoniden 457

Die Ptolemäer 458

Die Seleukiden 460

Die Cornelii Scipiones und ihre Familienverbindungen (3./2. Jh. v.Chr.) 462

Die Familie von Constantinus dem Großen 463

Die julisch-claudische Dynastie 464

Glossar zu politischen und militärischen Institutionen 466

Republikanische Beamtenlaufbahn 476

Geldsysteme, Maße und Gewichte 477

Quellen 479

Autoren 479

Quelleneditionen 485

Wichtige in den Altertumswissenschaften gebräuchliche

Abkürzungen 488

Bibliographie 491

Karten 523

Zeitalter der griechischen Kolonisation 525

Griechenland, Ägäis und die Westküste Kleinasiens im

5. Jh. v. Chr. 526

Die Ausbildung der hellenistischen Großreiche 527

Athen. Die wichtigsten Denkmäler der klassischen Zeit 528

Das Werden des republikanischen Rom 530

Das Imperium Romanum um 100 v. Chr. 531

Das Imperium Romanum zur Zeit des Septimius Severus 532

Das Imperium Romanum nach der Neuordnung durch Diocletianus und Constantinus 533

Rom. Forum Romanum und Kaiserfora 535

Rom. Die wichtigsten Denkmäler 536

Byzantion - Konstantinopolis 538

Namenregister 539

Ortsregister 544

Bildquellen 549 


\section{VORWORT}

Ein Handbuch, das Studierenden der Geschichtswissenschaft, der Archäologie und der Klassischen Philologie, aber darüber hinaus auch Geschichtslehrern und allgemein allen historisch Interessierten einen Überblick über die Geschichte der Antike bietet und zugleich Fragestellung und Methodik der modernen Althistorie vermittelt, war bislang ein Desiderat und bedarf insofern keiner ausführlichen Rechtfertigung.

Obgleich die Eigenständigeit sowie die Kontinuität der griechischen und der römischen Geschichte betont werden, begreifen die Herausgeber und die Autoren des vorliegenden Bandes die Geschichte der Antike von den Dark Ages bis hin zur Spätantike als eine Einheit, als die Geschichte des Mittelmeerraumes in der Zeit vom Beginn des 1. Jahrtausends v. Chr. bis zur Mitte des 6. Jahrhunderts n. Chr. Die Einbeziehung der Kulturgeschichte sowie der Sozial- und Wirtschaftsgeschichte in die Darstellung und der begrenzte Umfang eines Studienbuches machten eine Beschränkung auf die grundlegenden Fakten, Ereignisse und Prozesse notwendig. Den Autoren ist durchaus bewusst, dass viele historisch wichtige Entwicklungen - und dies gilt gerade für die politische Geschichte - nicht ausführlich beschrieben, sondern nur in Umrissen skizziert werden konnten.

Die Herausgeber und Autoren danken allen, die zum Entstehen dieses Bandes beigetragen haben, den wissenschaftlichen Mitarbeiterinnen und Mitarbeitern, den studentischen Hilfskräften und den Sekretärinnen an den Universitätsinstituten, insbesondere aber auch Dr. Oliver Schütze und Frauke Lätsch, die den Band im Lektorat des Metzler-Verlages mit großem Engagement betreut haben. 